\title{
Orthodontic Management of Class-I crowding in an adult male: A case report
}

Mahamud AMS ${ }^{1}$ BDS, Taher MA ${ }^{2}$ BDS, Sattar MH ${ }^{3}$ BDS, DDS, MCPS and Hossain MZ ${ }^{4}$ BDS, PhD

\begin{abstract} were achieved by edgewise orthodontic therapy.
\end{abstract}

A 20 years old male presented with Class-I malocclusion with crowding and lock bite on upper right and left lateral incisors. Treatment involved extraction of all first premolars. The alignment of teeth in both arches

Key Words: Class I malocclusion, crowding, edgewise orthodontic therapy (Bangladesh Journal of Orthodontics and Dentofacial Orthopedics, October 2012, Vol. 3, No. 1, p 34-37).

2. Correct the crossbite.

3. Establish and maintain a Class I molar and canine relationship.

4. Establish normal overjet and overbite.

5. Establish and maintain occlusal harmony and interdigitation for improved aesthetics and proper function.

\section{INTRODUCTION}

Crowding of the teeth is the most common type of malocclusion at present. Undoubtedly it is related in part to the continuing reduction in jaw and tooth size in human evolutionary development. Jaw dimensions do seem to have a strong genetic control. Environmental factors must have played some role in the recent increase in crowding of the dental arches. ${ }^{1-3}$

\section{HISTORY AND DIAGNOSIS}

A 20 year old male came to the department of Orthodontics and Dentofacial Orthopedics, Dhaka Dental College and Hospital with the chief complaint of irregularities on upper and lower jaw.

The patient was in the permanent dentition. He had no relevant dental, medical or family history and had no history of previous orthodontic treatment.

On extraoral examination (Fig: 1) he had a symmetric face with a straight profile. Lips are competent. His TMJ was alright and had a normal path of closure.

Clinical examination (Fig.2) showed crowding in both upper and lower arch and upper right and left lateral incisors were in crossbite. There was total of $12 \mathrm{~mm}$ crowding in maxilla and $7 \mathrm{~mm}$ crowding in the mandibular arch. He had Class I molar relationship with $1.5 \mathrm{~mm}$ overjet and $3 \mathrm{~mm}$ overbite. There was no premature contact or any other pathology. Radiographic examination (Fig.3) showed a full permanent dentition and a Class I skeletal pattern (Fig.4).

\section{TREATMENT OBJECTIVES}

Considering the above findings the objectives of orthodontic treatment of this patient were to -

1. Eliminate the crowding present in the upper and lower arch.

\section{TREATMENT PLAN AND PROGRESS}

Due to the severity of crowding, the first option of treatment plan was to extract all the first premolars to provide space for alignment. Standard edgewise 0.018 -inch slot bracket was bonded, Anchorage was enforced with a anchorage plate (Fig.5), Initial leveling was done with the use of 0.014-inch stainless steel arch wire with multiloop over 3 months. Then upper canines are retracted by using segments of elastomeric chain on 0.016-inch stainless steel archwires and a nickel-titanium coil spring. After closing the extraction space, 0.014 inch stainless steel with ' $L$ ' loops was placed to correct the cross bite of upper lateral incisors. In this stage bite opened by using posterior bite plane to free the lock.

In the lower arch, our approach was by sectional arch wire. As the lower canines were out of the arch, first canine retraction was done by sectional arch wire (Fig.6). Then leveling and alignment was done by 0.014 multiloop arch wires (Fig.6). The remaining extraction space on both arches was closed with tear drop contraction loops on $0.016 \times 0.022$ inch rectangular stainless steel arch wires (Fig.7).

After arch coordination and finishing, the appliance was removed, retention involved upper and lower removable begs retainer (Fig.9).

${ }^{1}$ Dr. A M Sohal Mahmud BDS, FCPS Trainee (Orthodontics and Dentofacial Orthopaedics), ${ }^{2}$ Dr. Md Abu Taher BDS, FCPS Trainee (Orthodontics and Dentofacial Orthopaedics), ${ }^{3}$ Dr. M H Sattar BDS, DDS, MCPS and ${ }^{4}$ Prof. Dr Md. Zakir Hossain BDS, PhD, Professor \& Head, Department of Orthodontics and Dentofacial Orthopaedics, Dhaka Dental College \& Hospital 


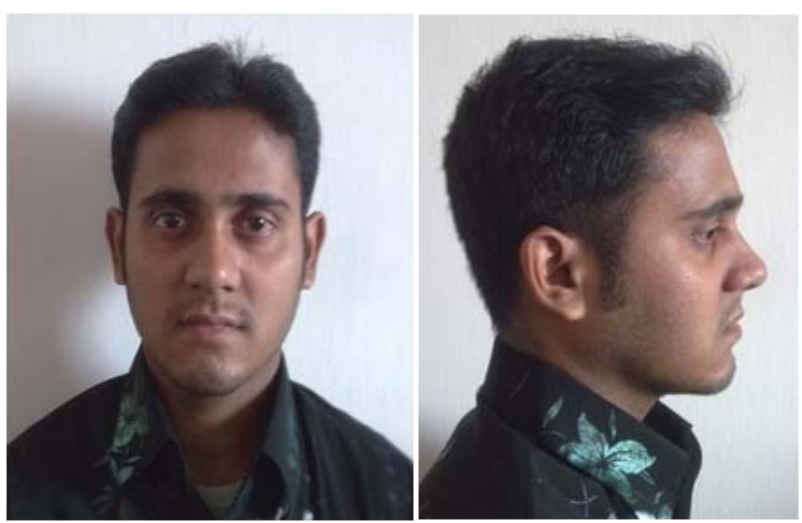

Fig.1: Pretreatment facial photographs.
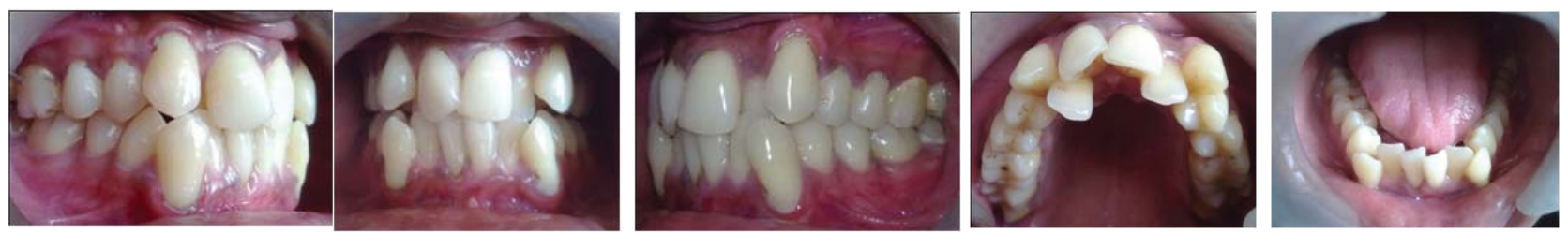

Fig.2: Pretreatment intraoral photographs.
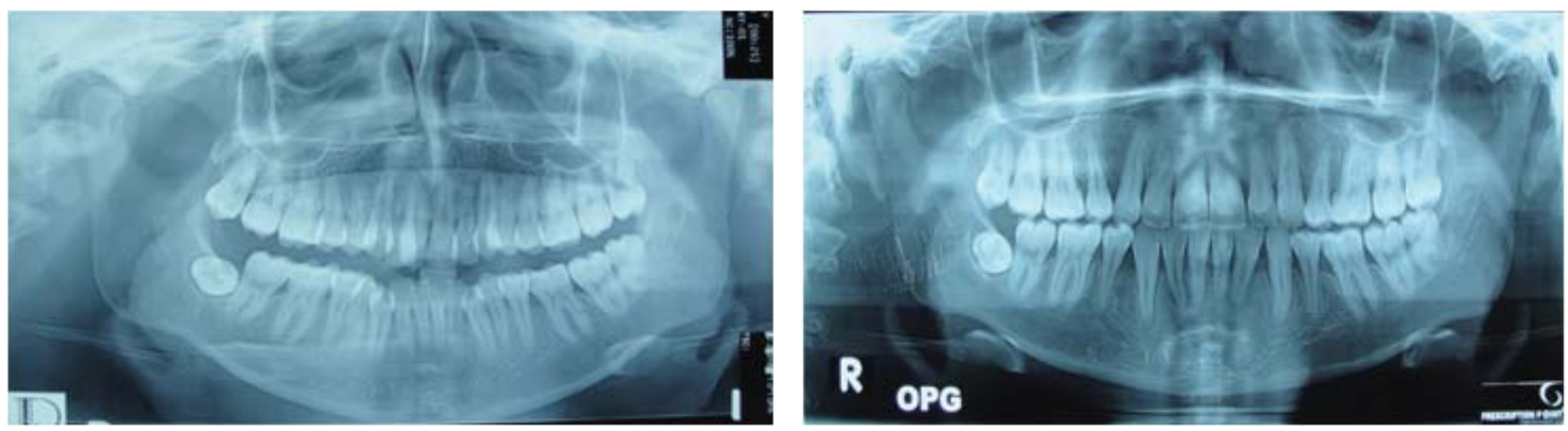

Fig.3: Panoramic Radiograph before (A) and after treatment (B)
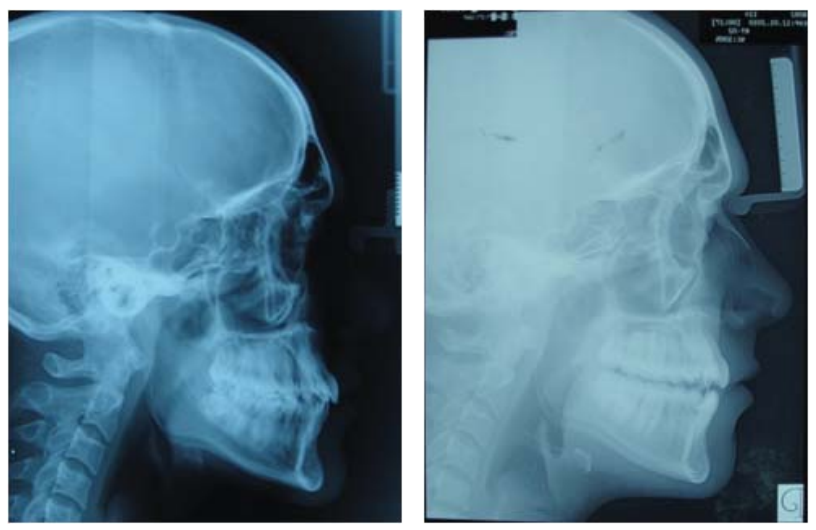

Fig.4: Cephalogram before (A) and after treatment (B) 


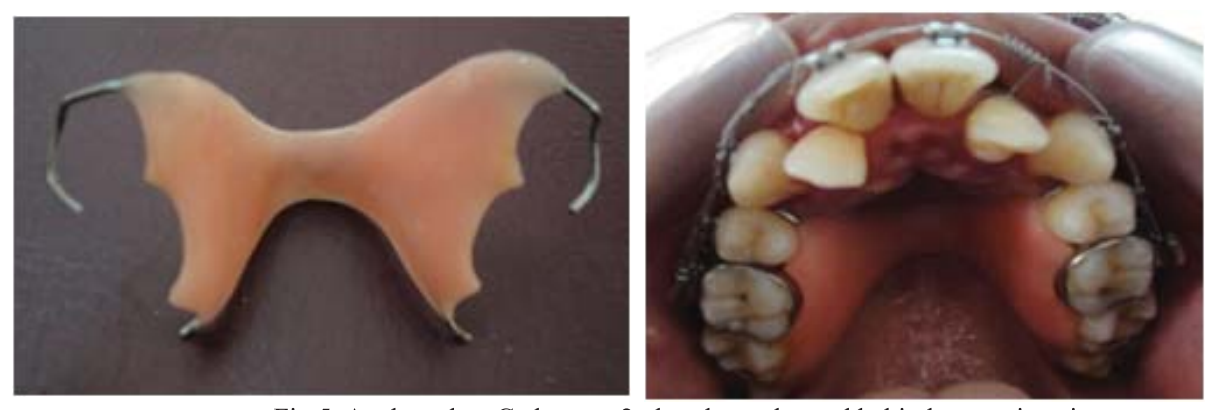

Fig.5: Anchor plate C clasp on 2nd molar and guard behind extraction site.
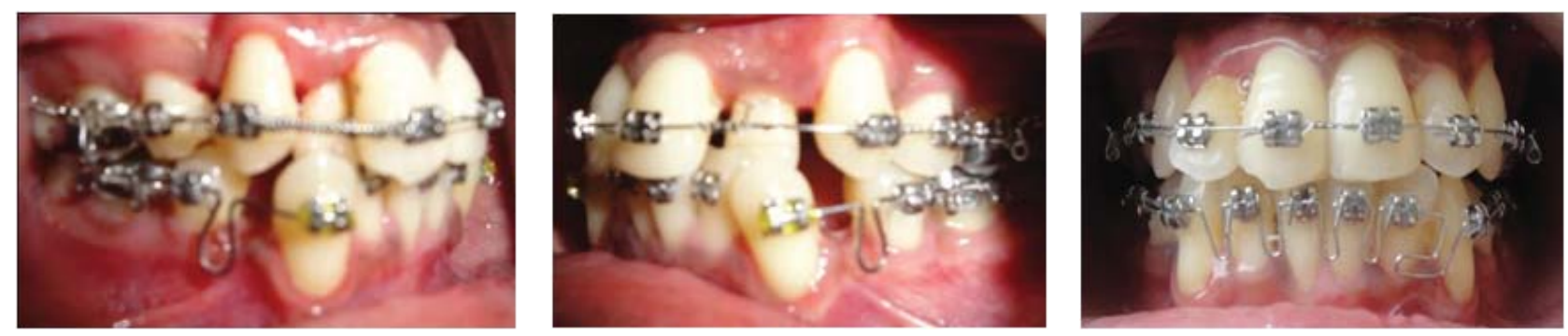

Fig.6: Canine retraction done by sectional arch wire on $0.016 \mathrm{x} 0.022$ inch rectangular stainless steel
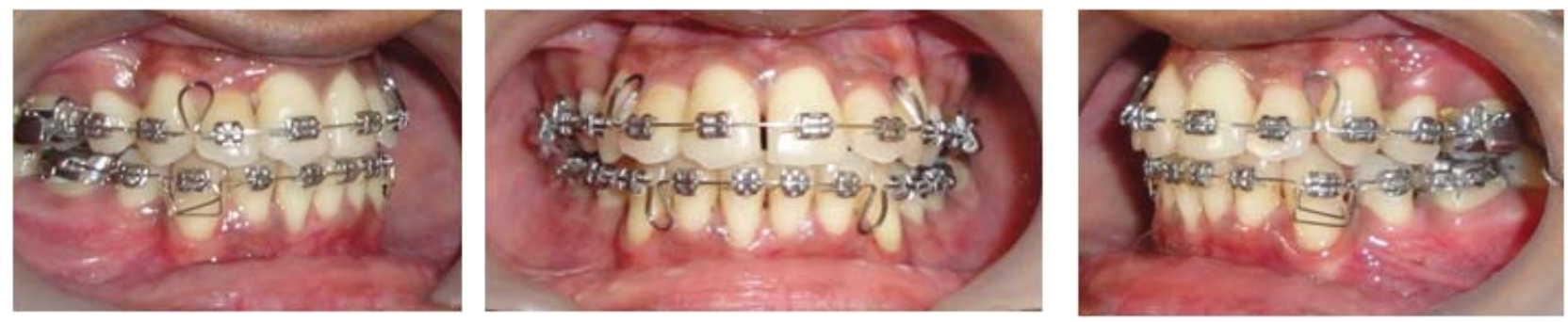

Fig.7: Arch contraction with tear drop loops on $0.016 \times 0.022$ inch rectangular stainless steel arch wires
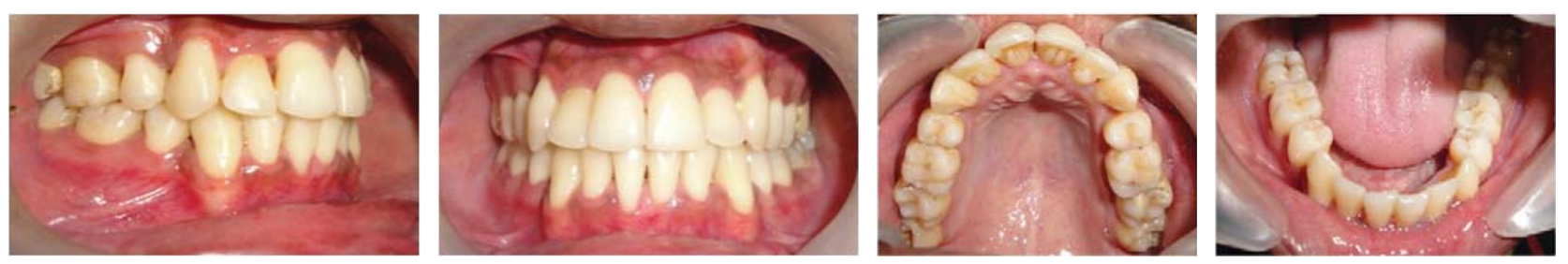

Fig.8: Post-treatment intraoral photographs.
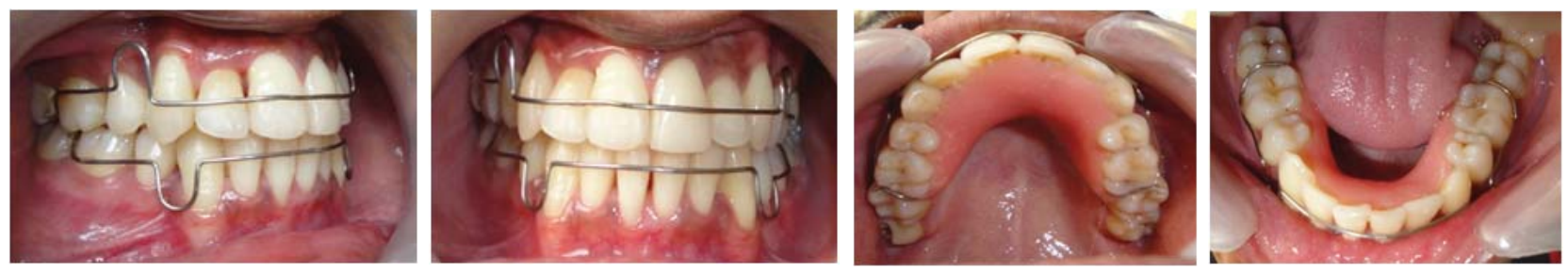

Fig.9: Retention by Begs retainer. 

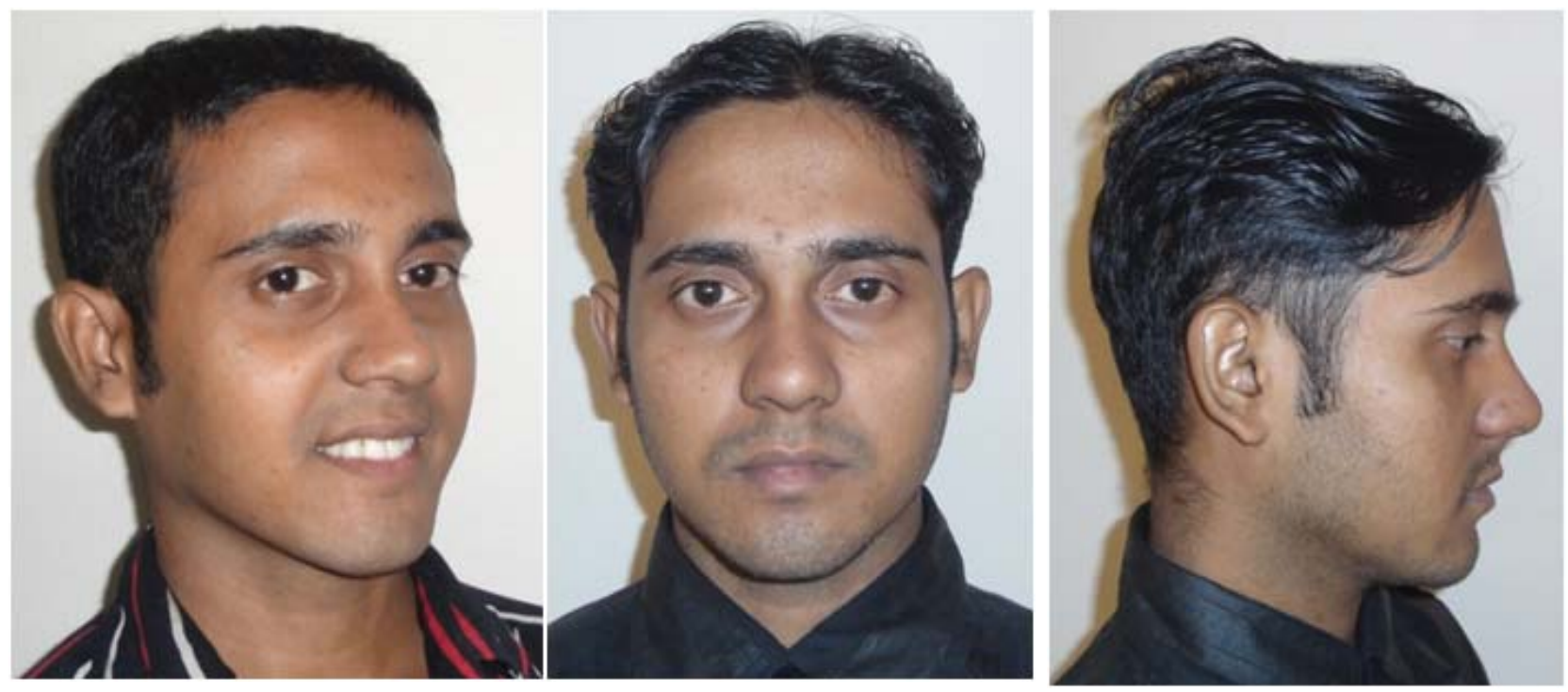

Fig.10: Post-treatment facial photographs.

\section{RESULTS AND DISCUSSION}

Total treatment time was 24 month, this is partly related to the long treatment time required to totally retract the canines. Post treatment records show that the treatment objectives were achieved. Facial photographs (Fig.10) show an improved profile and an attractive smile. Class I canine and molar relationships were established with canine-protected occlusion. Ideal overjet and overbite were achieved. Proper alignment and nice gingival contour were attained (Fig.8).

Post treatment panoramic radiographs (Fig. 3B) show good parallelism of roots and normal structure of the periodontium. No sign of root resorption was seen.
The post-treatment lateral cephalometric radiograph (fig.4B) showed a balanced facial profile. Cephalometric analysis showed a Class I skeletal relationship, the ANB angle decreased slightly. Dental measurements did not change significantly. A functional and good-looking occlusal result was achieved. The patient was satisfied with his teeth and appearance.

\section{REFERENCES}

1. Proffit WR, Fields HW. Contemporary Orthodontics. 4th ed. St Louis; Mosby; 2001;P-159.

2. Proffit WR, et al.: The Biological Basis of Orthodontic Therapy. In Contemporary Orthodontics. 4th edition. St. Louis: Missouri; 2007:331-358.

3. Proffit WR, et al.: Mechanical Principles in Orthdoontic Force Cotnrol. In Contemporary Orthdontics. 4th edition. St. Louis, Missouri; 2007:360-361

\section{Correspondence}

\section{Dr. A.M.Sohal Mahamud BDS}

FCPS-II Trainee

Dept. of Orthodontics and Dentofacial Orthopedic

Dhaka Dental College and Hospital

Mirpur-14, Dhaka-1206

Mobile: +8801716213184, E-mail: shoal_sdch@yahoo.com 